\title{
Deneyimin kompozit rezinlerin renk seçimi üzerine etkisinin bir spektrofotometre kullanılarak değerlendirilmesi
}

\author{
Duygu Recen*, Banu Önal, Lezize Şebnem Türkün \\ Restoratif Diş Tedavisi Anabilim Dalı, Diş Hekimliği Fakültesi, \\ Ege Üniversitesi, İzmir, Türkiye
}

\section{ÖZET}

AmAÇ: Çalışmanın amacı farklı deneyim düzeylerinde olan diş hekimlerinin renk algılarının bir spektrofotometre ile karşılaştırmalı olarak değerlendirmesidir.

GEREÇ VE YöNTEM: Çalışma, araştırmaya gönüllü olarak katılmayı kabul eden, Ege Üniversitesi Diş Hekimliği Fakültesi 4. sınıf öğrencileri üzerinde gerçekleştirildi. Bu öğrenci grubundan 100 gönüllünün sağ üst santral dişlerinin renk ölçümü $\mathbf{4}$ farklı araştırmacı tarafından geleneksel yöntemle yapılıp bir spektrofotometre ile karşılaştırıldı. Araştırmacılar 2 öğretim üyesi, 1 uzmanlık öğrencisi ve 1 diş hekimliği son sınıf öğrencisiydi. Renk seçimi öncesinde, araştırmacılara Ishiara testi uygulandı ve renk körü olmadıkları saptandı. Araştırmacılar gün ışığından faydalanarak, günün aynı saatinde, aynı dental ünitte, Vita Classical renk skalası kullanarak, renk seçme prensiplerine uygun olacak şekilde, sağ üst santral dişlerin renklerini tespit ettiler. Ölçümler tamamlandıktan sonra, uzmanlık öğrencisi tarafından SpectroShade Micro cihazı kullanılarak aynı dişin renk ölçümü tekrar edildi. Gözlemciler ve spektrofotometre arasındaki renk eşleşme oranı yüzde olarak hesaplandı ve gruplar arasındaki fark istatistiksel olarak Wilcoxon testi ile değerlendirildi $(p<0.05)$.

BULGULAR: Öğretim üyeleri ve uzmanlık öğrencisinin birbirleriyle olan karşılaştırmalarında anlamlı bir fark bulunamadı. Spektrofotometre ile karşılaştırıldığında, uzmanlık öğrencisinin renk tayini, cihaz ile istatistiksel olarak benzerdi ( $p>0.05$ ) ve doğru renk eşleştirme oranı diğer araştırmacılardan yüksekti. Diğer taraftan, son sınıf öğrencisi ile uzmanlık öğrencisi ve cihaz arasında istatistiksel olarak anlamlı farklılıklar saptandı $(p<0.05)$.

Sonuç: Yapılan çalışmadan elde ettiğimiz sonuçlara göre, renk algısının klinik deneyim ile geliştirilebile-

Makale gönderiliş tarihi: 26 Mayıs 2015; Yayına kabul tarihi: 07 Ağustos 2015 *iletişim: Duygu Recen, Ege Üniversitesi Diş Hekimliği Fakültesi, Restoratif Diş Tedavisi AD, 35040 Bornova, İzmir, Türkiye;

e-posta: recenduygu@ hotmail.com ceği sonucuna varıldı. Doğru bir renk seçimi yapabilmek için hekimlerin zor olgularda spektrofotometrik cihazlara da başvurmalarının yararlı olabileceğini düşünmekteyiz.

ANAHTAR Kelimeler: Görsel renk seçimi; renk; spektrofotometre

Kaynak Göstermek İçin: Recen D, Önal B, Türkün LŞ. Deneyimin kompozit rezinlerin renk seçimi üzerine etkisinin bir spektrofotometre kullanılarak değerlendirilmesi. Acta Odontol Turc 2016;33(1):12-7

EрітöR: Güven Kayaoğlu, Gazi Üniversitesi, Ankara, Türkiye

YAYıN HAKKI: () 2016 Recen ve ark. Bu eserin yayın hakkı Creative Commons Attribution License ile ruhsatlandırılmıştır. Sınırsız kullanım, dağıtım ve her türlü ortamda çoğaltım, yazarlar ve kaynağın belirtilmesi kaydıyla serbesttir.

[Abstract in English is at the end of the manuscript]

\section{Giriş}

Günümüzde estetik ve etkili bir gülüş hastalar için en az diş sağlığı kadar önemlidir. Dudak, yüz ve birbiri ile uyum içinde dizilmiş, uygun renk, form, yüzey özelliklerine sahip dişler kişinin iletişim becerisini ve kendine olan güvenini arttırır. ${ }^{1-3}$ Diş hekimliğindeki gelişmelerle estetik ön plana çıkmış ve renk, en az form ve fonksiyon kadar önemli hale gelmiştir. Seçilen rengin doğal dişlerle uyumlu olması hasta memnuniyetini arttırır ve restorasyon değişimi ile oluşacak ekstra maliyetlerin önüne geçer. ${ }^{4}$

İnsan gözü 400-700 nm dalga boyu arasındaki ışığı görebilmektedir. Renk ise ışığın gözün retinasına ulaşmasıyla ortaya çıkar. ${ }^{5,6}$ Işık dişe ulaştığında dişin içinden geçebilir, diş yüzeyinden düzgün veya dağınık bir şekilde yansıyabilir ya da soğurulabilir. ${ }^{1}$ Diş hekimliğinde Munsell renk sistemi ve Commision Internationale de l'Eclairage (CIE) renk sistemi kullanılır. En eski renk sistemi 1905 yılında geliştirilen Munsell renk sistemidir. Bu sistemde hue (renk tonu), value (parlaklık), chroma (yoğunluk) olmak üzere 3 değişken bulunur. Hue; bir renk grubunu diğer renk grubundan ayıran, rengin tonu, çeşidi, karakteridir. Bir cisimden geri dönen 
ışık miktarı ise value değeridir. Diş renginin seçiminde en önemli değer olan value, rengin açıklık veya koyuluğudur. Rengin doygunluğu chroma adını alır. Yoğunluk, parlaklıkla ters orantılıdır. ${ }^{7}$ CIE'ye göre renk polikromatik görsel bir algıdır. Bu sistemde $L^{*}, a^{*}, b^{*}$ parametreleri kullanılır ve 3 boyutlu olarak yaklaşık renk aralığı hesaplanabilir. ${ }^{6}$

Renk seçimi için görsel ve aletli sistemler olmak üzere iki yöntem kullanılmaktadır. ${ }^{4,8}$ En sık tercih edilen renk seçim yöntemi görsel yöntemdir. ${ }^{1,4}$ Görsel yöntemle yapılan renk seçiminde doğal diş seramik, plastik veya rezinden yapılmış skalalarla karşılaştırılır. ${ }^{9}$ Günümüzde yaygın olarak kullanılan, diş hekimlerinin genellikle beyazlatma ve restoratif işlemlerde tercih ettiği skala Vita Classical (Vita Zahnfabrik, Bad Sackingen, Almanya) skalasıdır. Skala 16 renkten oluşmaktadır. ${ }^{8,10}$ Vita Classical skalasında yoğunluk, A: kırmızımsı kahverengi, B: kırmızımsı sarı, C: gri, D: kırmızımsı gri olmak üzere harflerle ifade edilir. ${ }^{7}$ Rakamlarsa rengin doygunluğunu ifade eder. Vita Classical skalası parlaklığa göre; B1, A1, A2, D2, B2, C1, C2, D4, D3, A3, B3, A3.5, B4, C3, A4, C4 olarak sıralanmaktadır. ${ }^{5}$ Vita Classical skalasında renklerin gruplandırılmasının sistematik olmaması ve doğal diş renkleriyle yeterli düzeyde doğru eşleme sağlanamaması sebebiyle yeni skala sistemleri geliştirilmiştir. Daha geniş renk aralığına sahip olan, doğal diş renginin doğru ve sistematik bir şekilde tespit edilmesine imkan sağlayan Vita Toothguide 3D-MASTER (Vita Zahnfabrik) 1998 yılında piyasaya sürülmüştür. 26 renkten oluşan bu skalada renkler yoğunluğa göre vertikal yönde; tonlarına göre ise horizontal yönde sıralanmıştır. Renk tonu kodlamasında L: sarı tonu, R: kırmızı, M: sarı, kırmızı tonlarının arasını ifade eder. Harflerin önündeki rakamlar renk değerini, harflerden sonra gelen rakamlar ise renk yoğunluğunu gösterir. Günümüzde en yaygın kullanım alanı bulan skaladır. ${ }^{11}$

Doğal dişler renk seçimini zorlaştıran birçok özelliğe sahiptir. Dişin küçük, uzun, geniş olması, yüzey özelliklerinin düzgün olup olmaması, translusent özellikleri dişin rengini etkiler. Ayrıca renk seçimi yapılacak dişlerin kuru olması yanlış sonuca sebep olur. ${ }^{1,9,11}$ Görsel renk seçimi oldukça subjektiftir. Tat alma, duyma, koklama gibi, rengin algılanması da kişiden kişiye değişir. ${ }^{6}$ Gözün ışığı algılama şekli beynin bunu nasıl yorumladığı, hekimin deneyimi, yaşı, cinsiyeti, psikolojik etmenler, ortamın ışıklandırılması ve göz yorgunluğu da seçilen rengi değiştirmektedir. ${ }^{7}$ Seçim yapılan odanın rengi, hastanın makyajı ve ortam aydınlatması da yanıtıcı sonuçlar elde etmemize neden olabilir. ${ }^{4}$ Rengin ışık kaynağına bağlı olarak farklı görülmesine metamerizm denir. Renk ölçümü yapılan ortamın aydınlatması değişince, metamer özellik gösteren cisimler birbiriyle aynı renkte görülmez. Metamerizmi engellemek veya en aza indirgemek için renk tespiti yapılan ortamın aydınlatma koşullarını olabildiğince standardize etmek gerekir. ${ }^{7}$ $5500 \mathrm{~K}$ sıcaklığındaki gün ışığının renk seçimi için en uygun ışık olduğu düşünülmektedir.,12 Kuzey ülkelerinde havanın daha kapalı olması alınan rengi etkilemektedir. ${ }^{12}$ Günün farklı saatlerinde güneş ışınlarının geliş açısının değişmesi sebebiyle standardizasyon için suni aydınlatma intiyacı doğmuştur. Yaygın olarak akkor filamanlı ve floresan lambalar kullanılmaktadır. 8002700 lux aydınlatma sağlayan lambalar renk seçiminde kullanılmaya uygundur. ${ }^{8}$ Gün ışığında ölçüm yapılacaksa, 12:00 ile 15:00 arası en uygun saat aralığı olarak belirlenmiştir. ${ }^{7,12}$ Diş renginin çeşitliliği gingivalden insizale doğru arttığından, renk seçiminde dişin orta üçlüsü referans alınmalıdır. ${ }^{1}$ Kişinin sağlık durumu da renk seçimini etkiler. Renk körü olduğu tespit edilen en az 3 yıl deneyimi olan diş hekimlerinin yaptığı bir çalışmada; renk körü olan hekimlerin renk seçimindeki başarı oranları normal görme yetisine sahip olanlardan daha az bulunmuştur. ${ }^{4}$

Skalaların doğal diş rengini yansıtmaması, mevcut renk aralığının yetersiz olması ve piyasadaki skalaların birbirinden farklı olması görsel renk seçiminin dezavantajlarıdır. ${ }^{11}$ Sonuçların istatistiksel olarak değerlendirilmesi ve daha objektif, hızlı, tekrarlanabilir ölçüm yapılması için aletli renk seçim yöntemlerine ihtiyaç duyulmuştur.7,10,13 Kolorimetreler, RGB cihazları, spektrofotometreler, spektroradyometreler aletle renk seçme işlemlerinde kullanılan cihazların bazılarıdır. ${ }^{12}$ Rengin geçirgenliği, yansıması ve soğurulmasını ölçen cihazlara spektrofotometre denilmektedir. Spektrofotometreler önceden belirlenen renk kodlarıyla dişlerin rengini verirler. ${ }^{7,8}$ Pahalı olmalarına karşın uzun ömürlü ve yüzey rengini ölçmede kullanışlı cihazlardır.4,12,14

Bu çalışmanın amacı, farklı deneyim düzeylerinde olan diş hekimlerinin renk algılarının bir spektrofotometre ile karşılaştırmalı olarak değerlendirmektir.

\section{Gereç Ve Yöntem}

Çalışmamız Ege Üniversitesi Diş Hekimliği Fakültesi 4. sınıf öğrencilerinden oluşan, üst santral dişlerinde çürük veya restorasyonu bulunmayan, beyazlatma işlemi uygulanmamış, sağlıklı, 20-25 yaş arasında, araştırmamıza gönüllü olarak katılmayı kabul eden, 100 kişi üzerinde yapıldı.

Cinsiyetin renk seçimi üzerine etkisinin önüne geçmek için tüm araştırmacılar kadın seçildi. Araştırmacılar 2 öğretim üyesi (Ö1, Ö2), 1 uzmanlık öğrencisi (U) ve 1 diş hekimliği son sınıf öğrencisinden (S) oluşmaktaydı. Araştırmacılara Ishiara testi uygulandı ve renk körü olmadıkları tespit edildi. Tüm araştırmacılara renk, ışık, 
Vita Classical (Vita Zahnfabrik, Bad Sackingen, Almanya) renk skalası ve SpectroShade Micro (MHT Optic Research, Niederhasli, İsviçre) cihazı ile ilgili bilgi verildi.

Gönüllülere çalışmamız hakkında bilgi verilip 'onam formu' imzalatıldı. Öğrencilerin 11 numaralı dişleri çalışmaya dahil edildi. Günün aynı saatinde, aynı dental ünitte, gün ışığından faydalanılarak 4 farklı araştırmacı tarafından Vita Classical renk skalası ile, renk seçme prensiplerine uygun olacak şekilde, dişlerin kuru olmamasına özen gösterilerek, dişlerin orta üçlüsünden renk seçimi yapıldı. Gözlemcilere renk seçimi ile ilgili bir süre sınırı konulmadı. Göz 5 sn içinde yorulacağı için, nötral bir yüzeye bakılarak dinlendirilmesi gerektiği hatırlatıldı. Araştırmacıların birbirinden etkilenmemesi için seçilen renk klinik personeli tarafından kaydedildi.

Geleneksel yöntemle yapılan seçimler tamamlandıktan sonra, öğrenciler öğretim üyeleri tarafından randomize olarak uzmanlık öğrencisine yönlendirildi. Aynı dişler uzmanlık öğrencisi tarafından SpectroShade Micro cihazı kullanılarak tekrar ölçüldü. Alınacak her ölçümün öncesinde çapraz enfeksiyonun önüne geçmek için steril edilebilen ağız başlığı değiştirildi ve cihaz kalibre edildi. Ölçümler yapılırken cihazın açı kontrol mekanizmasına dikkat edildi. Doğru açıda meydana gelen horizontal yeşil çizgi ekranda görüldüğünde ölçümler yapıldı. Çalışmanın standardizasyonunu etkilememesi için elde edilen veriler, tek kör olarak farklı bir listede kaydedildi. Her diş için 3 ölçüm yapılarak ortalamaları alındı. Alınan görüntüler USB kablo aracılığı ile bilgisayar ortamında depolandı. Ölçüm sonuçları Vita Classical skalası ile uyumlu olarak toplandı ve renk dağıımları incelendi.

Veriler istatistiksel olarak Wilcoxon testi ile karşılaştırıldı $(p<0.05)$.

\section{BULGULAR}

Öğretim üyelerinin, uzmanlık öğrencisinin ve son sınıf öğrencisinin renk seçme başarılarının birbirine göre istatistiksel analiz verileri Tablo 1'de görülmektedir. Son sınıf öğrencisi ile uzmanlık öğrencisinin karşılaştırılması hariç, araştırmacılar arasında doğru renk eşleştirme ba-

Tablo 1. Araştırmacılar arası renk eşleşme istatistik verileri (p değerleri)

\begin{tabular}{lccc}
\hline Gözlemciler & S & U & 0̋2 \\
\hline Ö1 & 0.778 & 0.147 & 0.247 \\
Ö2 & 0.179 & 0.353 & \\
U & 0.007 & & \\
\hline
\end{tabular}

Ö1 ve Ö2: öğretim üyeleri, U: uzmanlık öğrencisi, S: son sınıf öğrencisi
Tablo 2. Araştırmacılar ve spektrofotometre arası doğru renk eşleşme istatistik verileri (p değerleri)

\begin{tabular}{lcccc}
\hline Gözlemci & 0̈1 & 0̈2 & U & S \\
\hline Cihaz & 0.018 & 0.039 & 0.264 & 0.001 \\
\hline
\end{tabular}

Ö1 ve Ö2: öğretim üyeleri, U: uzmanlık öğrencisi, S: son sınıf öğrencisi

şarısı bakımından fark olmasına rağmen; istatistiksel olarak anlamlı bir değere ulaşmadı. Her iki öğretim üyesi renk eşleştirme başarısına göre değerlendirildiğinde, aralarında istatistiksel olarak anlamlı bir fark saptanmadı. Her iki öğretim üyesinin renk eşleştirme başarısı, uzmanlık öğrencisi ile ayrı ayrı karşılaştırıldığında yine aralarında istatistiksel olarak anlamlı bir fark saptanmadı. Yine, her iki öğretim üyesinin son sınıf öğrencisi ile ayrı ayrı karşılaştırılmasında istatistiksel olarak anlamlı bir fark bulunamadı. Uzmanlık öğrencisinin rengi algılaması, son sınıf öğrencisi ile karşılaştırıldığında istatistiksel olarak anlamlı bir fark mevcuttu $(p<0.05)$.

Öğretim üyelerinin, uzmanlık öğrencisinin ve son sınıf öğrencisinin renk seçme başarısının, kullanılan spektrofotometreye göre istatistiksel analiz verileri Tablo 2'de görülmektedir. Öğretim üyelerinin ve son sınıf öğrencisinin cihazla olan karşılaştırılmasında anlamlı bir farklılıklar saptandı $(\mathrm{p}<0.05)$. Uzmanlık öğrencisi ve cihaz arasındaki doğru eşleştirme başarısı, diğer araştırmacıların cihazla olan eşleştirme başarısına göre daha yüksekti. İstatistiksel verilere dayanarak uzmanlık öğrencisi ile cihaz arasında fark olmadığı görüldü.

\section{TARTIŞMA}

Restorasyonlar fonksiyon ve fonasyon görevlerini yerine getirse bile, ancak hastanın diğer dişleriyle uyumlu bir renkte ise estetik olarak başarılı olurlar.

Görsel renk seçimi dezavantajları olmasına rağmen, herkes tarafından ulaşılabilirdir ve kullanımı basittir. Bu sebeple birçok hekim tarafından sıklıkla tercih edilmektedir. ${ }^{15}$ Paravina ve ark. ${ }^{16}$ yaptıkları bir araştırmada skalalar içinde Vitapan Classic (Vita Zahnfabrik) ve Vita Toothguide 3D Master renk skalalarının en çok kullanıldığını bulmuştur. Literatüre bakıldığında, seramik restorasyonlarda Vita Toothguide 3D Master renk skalası ile yapılan ölçümlerin daha doğru olduğu görülmektedir. ${ }^{17}$ Doğru bir renk seçimi yapmak için renk skalası ve restorasyon yapılacak materyalin aynı olması gerekmektedir. ${ }^{18}$ Çalışmamızda yaygın kullanım alanı olan ve birçok kompozit sistemi ile uyumlu Vita Classical skalası kullanılmıştır.

Renk seçiminde, seçim yapılacak dişlerin kurutulması hataya sebep olabilmektedir. Dişlerin kurutulması 
daha beyaz görünmelerine sebep olmaktadır. ${ }^{19} \mathrm{Bu}$ sorunun önüne geçmek için çalışmamız sırasında renk seçimi yapılacak dişlerin nemli olmalarına dikkat edilmiştir.

Literatüre bakıldığında cinsiyetin renk seçimi üzerine etkisini inceleyen araştırmalar mevcuttur. Yapılan bir çaış̧mada kadınların erkeklerden daha iyi renk seçtiği ve cinsiyetin renk seçiminde önemli bir role sahip olduğu bulunmuştur; ${ }^{9}$ ancak cinsiyetin renk seçimi üzerine etkisi olmadığını savunan araştırmalar da mevcuttur. ${ }^{20,21}$ $\mathrm{Bu}$ sebeple çalışmamız sadece kadın araştırmacılar arasında yapılmıştır.

Aydınlatmadaki değişiklikler algılanan renkte de değişikliklere neden olabilir. Kuzey ülkelerinde havanın daha kapalı olması seçilen rengi etkilemektedir. Günün farklı saatlerinde güneş ışınlarının geliş açısının değişmesi sonucunda aynı dişten farklı renkler alınabildiğinden standardizasyona intiyaç duyulmuştur. ${ }^{12}$ Bu sebeple çalışmamızda güneşli günlerde, günün aynı saatinde, aynı dental ünitte, aynı kişiler tarafından renk seçimi yapılmıştır.

Görsel renk seçiminde hataya sebep olabilecek bir diğer faktör ise hekimin yaşıdır. İlerleyen yaşla birlikte korneada ve lenste meydana gelen kahverengileşme sonucu renk algısı değişebilmektedir. ${ }^{19,22} \mathrm{Bu}$ bilgiye dayanarak araştırmamızda öğretim üyelerine göre daha genç olan uzmanlık öğrencisinin yaşına bağlı olarak daha fazla doğru eşleştirme yaptığını düşünmekteyiz.

Görsel renk seçiminden kaynaklanan hataların önüne, aletli renk ölçüm cihazları içinde en doğru sonucu veren spektrofotometreler ile geçilebilmektedir. Spektrofotometrenin görsel renk ölçüm yöntemiyle karşılaştırıldığı bir çalışmada, diş renginin bir spektrofotometre ile 5 kat daha doğru belirlenebildiği bulunmuştur. ${ }^{23}$ Bahannan ${ }^{24}$ ve Paul ve ark. ${ }^{25}$ spektrofotometreyi, görsel renk ölçüm yöntemiyle karşılaştırmışlar ve istatistiksel olarak spektrofotometrenin daha doğru sonuç verdiğini bulmuşlardır. Çalışmamızda kontrol grubu olarak kullandığımız SpectroShade Micro cihazı bir spektrofotometredir ve çoklu sensör sistemiyle çalışmaktadır. Dijital kamerası ve LED aydınlatması bulunmaktadır. LCD dokunmatik ekran doğru ölçüm yapabilmek için dişin pozisyonuna rehber oluşturur. Cihaz farklı skalalara uygun ölçüm yapabilmeyi sağlamaktadır. Uygun kalibre edilen spektrofotometrelerle alınan ölçümler güvenilir sonuçlar vermektedir. ${ }^{26}$ Araştırmacılar görsel ve aletli renk seçim yöntemlerinin birlikte kullanılmasını önermektedir.5,7,26

Renklerin algılanması ve ayırt edilebilirliğinin klinik deneyimle değişebildiği çeşitli çalışmalarla gösterilmiştir. ${ }^{23,27}$ Başkent Üniversitesi Diş Hekimliği Fakültesi öğrencileri ile Restoratif Diş Hekimliği uzmanları arasında renk eşleştirme başarısının karşılaştırıldığı bir çalışmada, klinik deneyimi olan Restoratif Diş Hekimliği uzmanlarının başarısı daha yüksek bulunmuştur. Araştırmamızın sonucuyla paralellik gösteren bu çalışmada klinik deneyimin renk seçiminde önemli olduğu gösterilmiştir. ${ }^{27}$

Dagg ve ark. ${ }^{28}$ yaptıkları bir çalışmada deneyimin renk belirlemedeki önemini araştırmış; teknisyen ve diş hekimlerinin, diş hekimliği fakültesi 3. sınıf öğrencilerine göre daha yüksek sayıda doğru eşleştirme yaptığını bildirmişlerdir.

Bazı çalışmalarda farklı eğitim ve deneyimdeki gözlemci grupları arasında renk eşleştirmede istatistiksel olarak anlamlı fark bulunmamasına rağmen, ${ }^{9,29}$ diş hekimliği öğrencilerinin klinik deneyimi olmayan 1. ve 2. sınıflar ve klinik deneyimi olan 3-5. sınıflar olarak gruplandırıldığı bir çalışmada, 3-5. sınıflardaki öğrencilerin renk eşleştirmede daha başarılı olduğu bulunmuştur. ${ }^{18}$

Diş hekimliğinde diğer uzmanlık dallarına oranla, protez ve restoratif diş tedavisi uzmanları renk eşleştirme problemiyle daha çok karşı karşıya gelmektedir. Çapa ve ark. ${ }^{20}$ yaptıkları bir çalışmada; uzman hekimler arasında renk eşleştirme başarısını karşılaştırmış, protez ve restoratif diş tedavisi uzmanlarının bu konuda daha başarılı olduklarını bulmuştur. Bu bulgu çalışmamıza paralel olarak renk seçiminin deneyimle öğrenilebilen bir yeti olduğunu desteklemektedir.

Literatür ile parelel olarak çalışmamızda klinik deneyimi yetersiz olan diş hekimliği son sınıf öğrencisi, klinik deneyimi daha fazla olan diğer araştırmacılara oranla başarısız çıkmıştır. Öğretim üyeleri arasında istatistiksel olarak anlamlı bir fark bulunamaması benzer klinik deneyim ve eğitimde olmalarına bağlandı. Renk seçme cihazını en çok kullanan uzmanlık öğrencisi, bu konuda klinik deneyimi fazla olduğu için en yüksek sayıda doğru renk seçimi yapmıştır.

Çalışmamızın aksine, deneyimin renk seçimi üzerine etkisi olmadığını savunan çalışmalar da literatürde mevcuttur. Klinik deneyimin renk seçimi üzerine etkisinin araştırıldığı bir çalışmada deneyimin renk seçimine etkisi olmadığı bulunmuştur. ${ }^{9}$ Ayrıca Lagouvardos ve ark. ${ }^{18}$ son sınıf diş hekimliği öğrencileri ve restoratif diş tedavisi bölümü doktora öğrencileri arasında yaptıkları araştırmada; deneyimin doğru renk seçiminde etkili olmadığını bulmuşlardır.

Işık kaynağı, obje ve göze bağlı olarak gözlemciler arası oluşan farklı renk algısı sorunu, aletli renk ölçüm cihazları kullanılarak çözülebilmektedir. Öğrenilebilen bir yeti olan renk seçiminde deneyim önemli olsa da; renk doğasının karmaşık oluşu, renk algısının subjektif olması ve birçok faktörden etkilenmesi gibi sebeplerden dolayı diş hekimleri görsel ve aletli renk seçim yöntemlerini birlikte kullanmalıdır. 


\section{SonUC}

Yapılan çalışmadan elde ettiğimiz sonuçlara göre, belirli düzeyde klinik tecrübenin doğru renk seçmede önemli olduğu bulundu ve renk algısının deneyim ile geliştirilebileceği sonucuna varıldı. Doğru bir renk seçimi yapabilmek için hekimlerin zor olgularda spektrofotometrik cihazlara da başvurmalarının yararlı olabileceğini düşünmekteyiz.

\section{TEŞEKKür VE AnMA}

Araştırmamıza gönüllü olarak katılan Ege Üniversitesi Diş Hekimliği Fakültesi öğrencilerine içtenlikle teşekkür ederiz.

Bu çalışma, 14-16 Mayıs 2015 tarihlerinde Londra, İngiltere'de düzenlenen ConsEuro 2015 Uluslararası Bilimsel Kongresi'nde poster bildirisi olarak sunulmuştur.

Çıkar çatışması: Yazarlar bu çalışmayla ilgili herhangi bir çıkar çatışmalarının bulunmadığını bildirmişlerdir.

\section{KAYNAKLAR}

1. Joiner A. Tooth color: a review of literature. J Dent 2004;32:3-12.

2. Tuncdemir AR, Polat S, Ozturk C, Tuncdemir MT, Gungor AY. Color differences between maxillar and mandibular incisors. Eur J Gen Dent 2012;1:170-3.

3. Dozić A, Kleverlaan CJ, El-Zohairy A, Feilzer AJ, Khashayar G. Performance of five commercially available tooth color-measuring devices. J Prosthodont 2007;16:93-100.

4. Polat $S$, Tunçdemir AR, Öztürk $C$, Tunçdemir MT. Renk körü ve renk körü olmayan diş hekimlerinin renk seçimindeki başarı oranlarının değerlendirilmesi. Cumhuriyet Üniv Diş Hek Fak Derg 2012;15:320-6.

5. Doğan A, Yüzügüllü B. Renk seçiminde güncel teknolojik gelişmeler. Atatürk Üniv Diş Hek Fak Derg 2011;4:65-72.

6. Chu JS, Devigus A, Paravina RD, Mieleszko AJ. Fundamentals of color shade matching and communication in esthetic dentistry, 2nd edn. Hanover Park, IL: Quintessence Publishing; 2010.

7. Bayındır F, Wee AG. Diş rengi seçiminde bilgisayar destekli sistemlerin kullanımı. Hacettepe Diş Hek Fak Derg 2006;30:40-6.

8. Keyf F, Uzun G, Altunsoy S. Diş hekimliğinde renk seçimi. Hacettepe Diş Hek Fak Derg 2009;33:52-8.

9. Haddad HJ, Jakstat HA, Arnetzl G, Borbely J, Vichi A, Dumfahrt H, et al. Does gender and experience influence shade matching quality? J Dent 2009;37:40-4.

10. Öngül D, Çelik D, İlbey D, Şermet B. Türk toplumundaki genç bireylerde diş renk dağılımının incelenmesi. İstanbul Üniv Diş Hek Fak Derg 2013;47:30-40.

11. Yılmaz SK, Şeker E, Ozan O, Meriç G, Yılmaz B. Hekimlerin ve dental teknisyenlerin vita tooth guide 3D master skalası ile renk seçimi başarılarının değerlendirilmesi. Cumhuriyet Üniv Diş Hek Fak Derg 2011;14:92100.

12. Sarafianou A, Kamposiora $P$, Papavasiliou G, Goula H. Matching repeatability and interdevice agreement of 2 intraoral spectrophotometers. J Prosthet Dent 2012;107:178-85.

13. Kısacık FÖ, Keçeci AD, Adanır N. Vital ağartma tedavilerinde başarının ve renk stabilitesinin ölçülmesi. S.D.Ü Sağlık Bilimleri Enstitüsü Dergisi 2012;3:89-95.

14. Kim-Pusateri S, Brewer JD, Dunford RG, Wee AG. In vitro model to evaluate reliability and accuracy of a dental shade-matching instrument. J Prosthet Dent 2007;98:353-8.

15. Curd FM, Jasinevicius TR, Graves A, Cox V, Sadan A. Comparison of the shade matching ability of dental students using two light sources. J Prosthet Dent 2006;96:391-6.

16. Paravina RD, O'Neill PN, Swift EJ Jr, Nathanson D, Goodacre CJ.
Teaching of color in predoctoral and postdoctoral dental education in 2009. J Dent 2010;38:e34-40.

17. Öngül $D$, Şermet B, Balkaya MC. Visual and instrumental evaluation of color match ability of 2 shade guides on a ceramic system. J Prosthet Dent 2012;108:9-14.

18. Lagouvardos PE, Diamanti H, Polyzois G. Effect of individual shades on reliability and validity of observers in color matching. Eur J Prosthodont Restor Dent 2004;12:51-6.

19. Trakyalı G. Diş rengi belirlenmesinde kullanılan yöntemler. EÜ Diş Hek Fak Derg 2013;34:1-10.

20. Capa N, Malkondu O, Kazazoglu E, Calikkocaoglu S. Evaluating factors that affect the shade-matching ability of dentists, dental staff members and laypeople. J Am Dent Assoc 2010;141:71-6.

21. Capa N, Malkondu O, Kazazoglu E, Calikkocaoglu S. Effects of individual factors and the training process of the shade-matching ability of dental students. J Dent Sci 2011;6:147-52.

22. Nguyen-Tri D, Overbury O, Faubert J. The role of lenticular senescence in age-related color vision changes. Invest Ophthalmol Vis Sci 2003;44:3698-704.

23. Judeh A, Al-Wahadni A. A comparison between conventional visual and spectrophotometric methods for shade selection. Quintessence Int 2009;40:e69-79.

24. Bahannan SA. Shade matching quality among dental students using visual and instrumental methods. J Dent 2014;42:48-52.

25. Paul S, Peter A, Pietrobon N, Hämmerle $\mathrm{CH}$. Visual and spectrophotometric shade analysis of human teeth. J Dent Rest 2002;81:57882.

26. Chu SJ, Trushkowsky RD, Paravina RD. Dental color matching instruments and systems. Review of clinical and research aspects. J Dent 2010;38:e2-16.

27. İnan H, Yapıcı DE, Şentürk Y, Toprak S, Çınar D, Yüzügüllü B. Başkent Üniversitesi Diş Hekimliği Fakültesi öğrencileri ile restoratif diş hekimleri arasında renk eşleştirme yetilerinin karşılaştırılması. Hacettepe Diş Hek Fak Derg 2008;32:56-63.

28. Dagg H, O'Connell B, Claffey N, Byrne D, Gorman C. The influence of some different factors on the accuracy of shade selection. J Oral Rehabil 2004;31:900-4.

29. Meireles SS, Demarco FF, dos Santos Ida S, Dumith Sde C, Bona $A D$. Validation and reliability of visual assessment with a shade guide for tooth-color classification. Oper Dent 2008;33:121-6.

\section{The effect of experience on composite resin shade selection in comparison to a spectrophotometer}

Abstract

OвJестіVE: The objective of this study was to compare the shade matching ability of dentists with different experience levels in comparison to a spectrophotometer.

Materials AND Method: Participants were selected from the volunteer fourth grade students of Faculty of Dentistry, Ege University $(n=100)$. A fifth year undergraduate student, a research assistant with 2 years of experience and two professors of restorative dentistry with at least 10 years of experience were included in this study as observers. Ishihara color blindness test was applied to all observers before taking shades. After taking the shades with conventional method by using Vita Classical shade guide, 
the research assistant took the shades again with SpectroShade Micro device. Agreement on shade matches was evaluated by percentage and compared using Wilcoxon test $(p<0.05)$.

RESULTS: When compared against each other, no statistically significant differences were found among the shade assignments of the professors and the research assistant. Compared against the spectrophotometer, the shade assignment of the research assistant was statistically similar to the device $(p>0.05)$ and the correct match rate of the research assistant was superior to the others.
Statistically significant differences were found between the fifth grade student's shade assignments and the research assistant's assignments as well as the device's readings $(p<0.05)$.

Conclusion: Within the limitations of this study, it was concluded that shade matching is a learnable process. In order to do a correct shade match in complicated situations, dentists may refer to spectrophotometric devices.

KEYWORDS: Color; spectrophotometer; visual shade selection 